\title{
Early Outcomes of Modified De Vega Annuloplasty for Functional Tricuspid Regurgitation at a Brazilian Hospital
}

Diogo Luiz de Magalhães Ferraz, ${ }^{\circledR}$ Karina Mascarenhas Bezerra Alves, ${ }^{\circledR}$ Larissa Almeida Barp Santos, ${ }^{\circledR}$ Girliney dos Santos Leandro, ${ }^{\oplus}$ Cristiano Berardo Carneiro da Cunha, ${ }^{\circledR}$ Rodrigo Mezzalira Tchaick, ${ }^{\circledR}$ Igor Correia Silva, João Paulo Segundo de Paiva Oliveira, Jeú Delmondes de Carvalho Júnior, ${ }^{\circledR}$ Felipe Ribeiro Walter, ${ }^{\circledR}$ Stephanie Steremberg Pires D'Azevedo, ${ }^{-}$Tais Lins Severo da Silva ${ }^{\circledR}$ Verônica Soares Monteiro, ${ }^{\circledR}$ Fernando Augusto Marinho dos Santos Figueira ${ }^{\circledR}$

Instituto de Medicina Integral Prof. Fernando Figueira - Cardiovascular Surgery, Recife, PE - Brazil

\section{Abstract}

Background: Right valve diseases are not benign, the tricuspid regurgitation has a significant impact on morbidity and mortality of patients.

Objectives: This study aimed to report the short-term results of tricuspid annuloplasty using the De Vega technique modified by Manuel Antunes.

Methods: A descriptive-analytical study was performed to evaluate the results of the tricuspid valvuloplasty performed at the Instituto de Medicina Integral Professor Fernando Figueira between 2012 and 2017. Data were collected by reviewing charts and databases of the Department of Cardiology and Cardiovascular Surgery of the institution. Those with rheumatic diseases or infective endocarditis with tricuspid valve involvement, or reoperation of the tricuspid valve were excluded. Student's t-test and McNemar's were used for statistical analysis. A p-value $<0.05$ was considered statistically significant.

Results: A total of 87 patients were studied, most of them were women (56.3\%). The most associated heart valve diseases were mitral regurgitation $(27.6 \%)$ and aortic regurgitation $(20.7 \%)$. There was a significant decrease in the degree of tricuspid regurgitation in the postoperative period, with $83.3 \%$ of patients with none or mild regurgitation and only $1.1 \%$ with severe regurgitation $(\mathrm{p}=0.0077)$.

Conclusions: In the current study, tricuspid valve annuloplasty using the modified De Vega technique was shown to be effective in the short term. Further studies are needed to evaluate the long-term results. (Int J Cardiovasc Sci. 2020; 33(5):472-478)

Keywords: Heart Valve Diseases/physiopathology; Cardiac Valve Annuloplasty/methods; Tricuspid Valve Insufficiency; De Vega Annuloplasty.

\section{Introduction}

In Brazil, a significant proportion of hospitalizations for cardiovascular diseases is due to heart valve diseases. ${ }^{1}$ Among these, tricuspid regurgitation (TR) is more common than tricuspid stenosis, which is a rare condition. In the

Mailing Address: Diogo Ferraz

Rua dos Coelhos, 300. Postal Code: 50070-5500, Boa Vista, Recife, PE - Brazil. E-mail: diogoferraz_@hotmail.com
Framingham study, the overall prevalence of moderate TR was $0.8 \%$, with a higher prevalence among women (up to 4.3 times greater than men). There is a frequent association of both tricuspid stenosis and TR with mitral valve disease. ${ }^{1,2}$

Historically, physicians and researchers have placed less importance to right heart valve disease because of
Diogo Luiz de Magalhães Ferraz, MD Cardiovascular Surgeon Instituto de Medicina Integral Prof. Fernando Figueira - IMIP diogo@cardioin.com.br 
its long, asymptomatic latency period, and the association of secondary TR with left heart valve disease. However, it has been recently observed that right valve diseases are not benign and have a significant and independent impact on morbidity and mortality. ${ }^{3}$ Mortality increases with the severity of TR: one-year survival rate among patients without the disease was $91.7 \%$; in patients with mild TR, 90.3\%; moderate TR, 78.9\%; and severe TR, $63.9 \%$.

TR does not cause many symptoms and is classified as primary ( 8 to $10 \%$ of severe cases) when results from organic tricuspid valve disease (e.g., endocarditis, rheumatic disease), and as secondary or functional $(90 \%$ of severe cases), when it is caused by volume overload and/or pressure overload in the right ventricle generated by pulmonary hypertension, left heart failure or right ventricular ischemia. Most of signs and symptoms of TR become more evident due to an increase in the right atrial pressure, culminating in heart failure in more severe cases. ${ }^{5-7}$

Treatment options for tricuspid valve disease have increased. Annuloplasty techniques can be divided in two groups: the first group consists of techniques of implantation of a prosthetic ring to restore the shape and size of the tricuspid ring, like the Carpentier's technique, and the second group consists of techniques that do not use the prosthetic ring, as in the modified De Vega annuloplasty, by Manuel Antunes. In the classical De Vega's annuloplasty, two continuous sutures running along the anterior and posterior portions of the tricuspid annulus (he free wall of the right ventricle) are performed. Therefore, the septal portion of the annulus is spared for protection of the conduction system of the heart. ${ }^{8}$ In 1983, aiming to improve the distribution of the tension of the valve suture, Manuel Antunes proposed the insertion of Teflon pledgets in each space between the suture lines, creating the modified De Vega technique. ${ }^{9}$

The De Vega technique is easily reproducible and applicable, low cost, relatively fast, and relatively free of complications. However, in a medium-term postoperative follow-up of annuloplasties, the incidence of recurrence of tricuspid insufficiency was higher after De Vega technique $(17.2 \%-13.7 \%)$ compared with the modified De Vega annuloplasty $(15.3 \%-7.7 \%) .{ }^{10}$

There are few studies in this area since the interest in right heart valve diseases has only recently increased. The present study was conducted with limited technology and scarce materials, provided by the Brazilian Unified Health System (SUS). Therefore, this research aims to add to the current knowledge on the theme and perform an early evaluation of tricuspid valve annuloplasty, performed with the modified De Vega technique, due to secondary tricuspid insufficiency.

\section{Methods}

A descriptive-analytical study was performed to evaluate the initial results of tricuspid annuloplasty using modified De Vega technique. The study was carried out at Instituto de Medicina Integral Professor Fernando Figueira (IMIP), and institute of integrative medicine, and data were collected by reviewing charts and databases of the Department of Cardiology and Cardiovascular Surgery at IMIP.

From May 2012 to April 2017, 87 consecutive patients who underwent modified De Vega procedure and other cardiac valve surgeries concomitantly in our institution were enrolled in the present study. Patients with rheumatic heart disease or infective endocarditis with tricuspid valve involvement or patients with a history of surgery for tricuspid valve disease were excluded.

All operations were performed with a conventional median sternotomy, cardiopulmonary bypass (CPB) with aortic and bicaval cannulation, and mild hypothermia $\left(32^{\circ}\right.$ to $34^{\circ} \mathrm{C}$ ). The aorta was cross-clamped and cold cardioplegia delivered. After the left heart valve surgery was finished, the aorta was released, and the heart was again perfused and beating.

The tricuspid annuloplasty consists of two continuous sutures using 3-0 or 4-0 polypropylene with Teflon-pledged sutures running along the anterior and posterior tricuspid annulus. The procedures were performed by five surgeons that used the same technique.

Preoperative echocardiography were performed in other institutions, and all postoperative echocardiography was performed at IMIP before hospital discharge.

The study complied with the principles of the National Health Council for research on human beings and was approved by the Research Ethics Committee of the IMIP. Certificate of Presentation for Ethical Consideration (CAAE): 58349516.7.0000.5201.

\section{Statistical analysis}

All statistical analysis was performed using Stata 12.1. The Kolmogorov-Smirnov test was used to test the normality of data. Continuous variables with normal distribution were expressed as mean and standard deviation. Descriptive statistics were used to characterize the patients, and proportions were used for categorical variables. 
For the analysis of the differences between pre and postoperative values of left ventricular ejection fraction (LVEF) the Student's paired t-test was used. The McNemar's test was performed to evaluate the efficacy of the treatment in reducing the degree of the tricuspid regurgitation. A p value of $<0.05$ was considered statistically significant.

\section{Results}

A total of 87 patients were submitted to tricuspid valve annuloplasty evaluation, 49 (56.3\%) were women. The median age was 41.8 years, the average height was $162.89 \mathrm{~cm}$, the mean weight was $66.13 \mathrm{~kg}$, and the median body mass index (BMI) was $24.83 \mathrm{~kg} / \mathrm{m}^{2}$.

Most patients had rheumatic disease $(65.51 \%)$, followed by bacterial endocarditis $(4.59 \%)$ (not tricuspid valve infective endocarditis, which was an exclusion criterion of this study) (Table 1).

Regarding comorbidities, $35.6 \%$ had systemic arterial hypertension, $21.8 \%$ chronic atrial fibrillation, and $18.4 \%$ of the patients were smokers. Heart valve diseases most associated with TR included mitral regurgitation (27.6\%) and aortic regurgitation (20.7\%). The most frequent signs and symptoms of heart failure were peripheral edema (35.6\%), murmur in other locations than the tricuspid valve $(14.9 \%)$ and nocturnal paroxysmal dyspnea (12.6\%). According to the New York Heart Association (NYHA) criteria, most patients $(n=57,93.4 \%)$ were classified as functional class II and III.

Of the 87 patients in the sample, $63(72.4 \%)$ underwent tricuspid annuloplasty with mitral valve surgery, $22(25.3 \%)$ tricuspid annuloplasty with aortic valve replacement, and $2(2.3 \%)$ underwent surgery of the three (tricuspid, mitral and aortic) valves.

In 67 patients $(77.0 \%)$, bioprosthesis was used to correct the other valve diseases.

The mean cross-clamp time was 68.29 minutes, and total cardiopulmonary bypass time was 129.04 minutes.

During the postoperative period, the mean intensive care unit (ICU) length of stay was 6.66 days, and mean hospital stay was 20.26 days. Fifty-eight patients (68.2\%) used vasoactive drugs.

The main postoperative complications were respiratory tract infection $(n=16,24.6 \%)$, followed by atrioventricular block $(\mathrm{n}=14,21.5 \%)$ and acute renal failure $(\mathrm{n}=11$ patients, $17 \%$ ); only $3(4.6 \%$ ) patients required permanent pacemaker implantation. Overall 30-day mortality was $6.9 \%(n=6)$ (Table 2).

\begin{tabular}{|c|c|c|}
\hline \multicolumn{3}{|c|}{ Table 1 - Baseline characteristics of patients } \\
\hline Preoperative variables & $\mathrm{n}(\%$ or $\pm \mathrm{SD})$ & $\mathbf{n}$ \\
\hline Female & $49(56.3 \%)$ & 87 \\
\hline Male & $38(43.7 \%)$ & 87 \\
\hline Age (years) & $41.8 \pm 16.7$ & 81 \\
\hline \multicolumn{3}{|l|}{ Anthropometric measurements } \\
\hline Height (cm) & $162.89 \pm 7.25$ & 57 \\
\hline Weight (kg) & $66.13 \pm 16.56$ & 73 \\
\hline BMI $\left(\mathrm{kg} / \mathrm{m}^{2}\right)$ & $24.83 \pm 5.70$ & 57 \\
\hline \multicolumn{3}{|l|}{ Echocardiographic data } \\
\hline LVEF (\%) & $56.19 \pm 12.77$ & 68 \\
\hline \multicolumn{3}{|l|}{ Etiology } \\
\hline Rheumatic disease & $57(65.51 \%)$ & 87 \\
\hline Infective endocarditis & $4(4.59 \%)$ & 87 \\
\hline $\begin{array}{l}\text { Rheumatic disease and infective } \\
\text { Endocarditis }\end{array}$ & $2(2.29 \%)$ & 87 \\
\hline Chagas disease & $1(1.14 \%)$ & 87 \\
\hline $\begin{array}{l}\text { Others (prosthesis dysfunction, } \\
\text { congenital, etc.) }\end{array}$ & $24(27.58 \%)$ & 87 \\
\hline \multicolumn{3}{|l|}{ Comorbidities } \\
\hline Systemic arterial hypertension & $31(35.63 \%)$ & 87 \\
\hline Chronic atrial fibrillation & $19(21.83 \%)$ & 87 \\
\hline Smoking & $16(18.39 \%)$ & 87 \\
\hline Diabetes mellitus & $9(10.34 \%)$ & 87 \\
\hline Alcoholism & $8(9.19 \%)$ & 87 \\
\hline Chronic kidney disease & $6(6.89 \%)$ & 87 \\
\hline COPD & $4(4.59 \%)$ & 87 \\
\hline Hypothyroidism & $3(3.44 \%)$ & 87 \\
\hline Paroxysmal atrial fibrillation & $1(1.14 \%)$ & 87 \\
\hline No comorbidities & $16(18.39 \%)$ & 87 \\
\hline Others & $10(11.49 \%)$ & 87 \\
\hline $\begin{array}{l}\text { BMI: body mass index; COPD: chr } \\
\text { LVEF: left ventricular ejection fract }\end{array}$ & $\begin{array}{l}\text { tive pulmonary } \\
\text { ndard deviation. }\end{array}$ & \\
\hline
\end{tabular}

Of the 87 patients in the sample, 34 patients $(39,08 \%)$ underwent reoperations after tricuspid valve repair. Comparative analysis of reoperations with first heart surgeries revealed that the mean aortic cross-clamp time was $74.78 \mathrm{~min}$ in reoperation and $63.87 \mathrm{~min}$ in the first 
Table 2 - Postoperative outcomes of the patients $(n=87)$

\begin{tabular}{lcc}
\hline Postoperative variables & n (\% or \pm SD) & n \\
\hline Mortality in 30 days & $6(6.89 \%)$ & 87 \\
ICU time (days) & $6.66 \pm 6.32$ & 66 \\
Length of stay (days) & $20.26 \pm 20.36$ & 50 \\
Use of vasoactive drugs & $58(90.6 \%)$ & 64 \\
\hline Echocardiographic data & & \\
\hline LVEF (\%) & $53,03 \pm 12.67$ & 65 \\
\hline Complications & & \\
\hline Respiratory tract infection & $16(24.6 \%)$ & 65 \\
Atrioventricular block & $14(21.5 \%)$ & 65 \\
Permanent pacemaker implantation & $3(4.6 \%)$ & 65 \\
Acute renal failure & $11(17 \%)$ & 65 \\
Pericardial effusion & $8(12.3 \%)$ & 65 \\
Cardiopulmonary resuscitation & $7(10.8 \%)$ & 65 \\
Urinary tract infection & $5(7.7 \%)$ & 65 \\
Low cardiac output syndrome & $2(2.3 \%)$ & 65 \\
Cardiac tamponade & $2(3 \%)$ & 65 \\
\hline Pneumothorax & $4(6.15 \%)$ & 65 \\
Mediastinitis & $4(6.15 \%)$ & 65 \\
Pleural effusion & $3(4,6 \%)$ & 65 \\
Sepsis & $3(4.6 \%)$ & 65 \\
\hline Atrial fibrillation & $2(3 \%)$ & 65 \\
\hline Stroke & & 65 \\
\hline
\end{tabular}

heart surgery. Mean cardiopulmonary bypass time was $143.36 \mathrm{~min}$ in reoperation and $119.20 \mathrm{~min}$ in the first heart surgery. Mean ICU time was 6.37 days for reoperations and 6.87 days for first surgeries, and the mean hospital stay was 23.06 days and 20.15 days, respectively. Thirtyday mortality was $12.2 \%$ among patients who underwent reoperation and $2.2 \%$ after the first heart valve surgery. In patients who underwent reoperation, the main complications were low cardiac output syndrome and cardiorespiratory arrest.

Analysis of echocardiographic data showed that there was no significant difference between pre- and postoperative mean LVEF (56.2\% vs. 53.03\%, respectively, $\mathrm{p}=0.0774$ ).

In the postoperative period, a significant reduction in the grade of TR was observed - 45 patients $(83.3 \%)$ had none or mild residual lesion, eight patients (14.81\%) had moderate TR and only one patient $(1.85 \%)$ continued with severe TR ( $\mathrm{p}=0.0077)$ (Figure 1) (Table 3).

\section{Discussion}

The epidemiological profile of the patients submitted to cardiac surgery in this study agreed with that found in the literature. High-surgical-risk patients have comorbidities and advanced symptoms, in addition to the inherent factors involved in valve replacement surgeries, such as an extracorporeal circulation time. Data of the literature have shown that tricuspid insufficiency is more common in women, ${ }^{2}$ there is a high prevalence of smoking in heart disease patients, ${ }^{12}$ and the most common comorbidities in association with valve disease are systemic arterial hypertension, chronic atrial fibrillation, and diabetes. ${ }^{13}$

The symptoms of patients with TR are variable. In general, there is a predominance of repercussions of left heart disease in case of secondary disease, ${ }^{14}$ and in advanced stage, the symptoms of right heart failure are prominent, ${ }^{3}$ with emphasis on peripheral edema and heart murmurs found in this study 6 associated with an advanced NYHA index (III and IV -57.4\%), ${ }^{15}$ which is an indicator of poor prognosis. ${ }^{16}$

The mean age found in this study (41.8 years) was lower than in other studies (56 years for valve surgeries and 58.7 years for heart surgeries). ${ }^{13}$ This may be justified by the fact that most of our patients had rheumatic diseases which affect younger patients.

In addition, tricuspid valve surgery represents an additional risk factor when performed in patients with other systemic and valve diseases, especially mitral valve disease and aortic valve disease. ${ }^{17,18}$ This association with the mitral valve is already well documented in the literature $^{1,2}$ and makes the approach of tricuspid valve surgery controversial, ${ }^{19}$ since the correction of mitral valve disease per se could reduce the repercussions of the tricuspid injury. ${ }^{20}$

The present study demonstrated the effectiveness of tricuspid valve repair surgery by the modified De Vega technique, with a significant reduction in the degree of TR. Most patients achieved a favorable and expected 


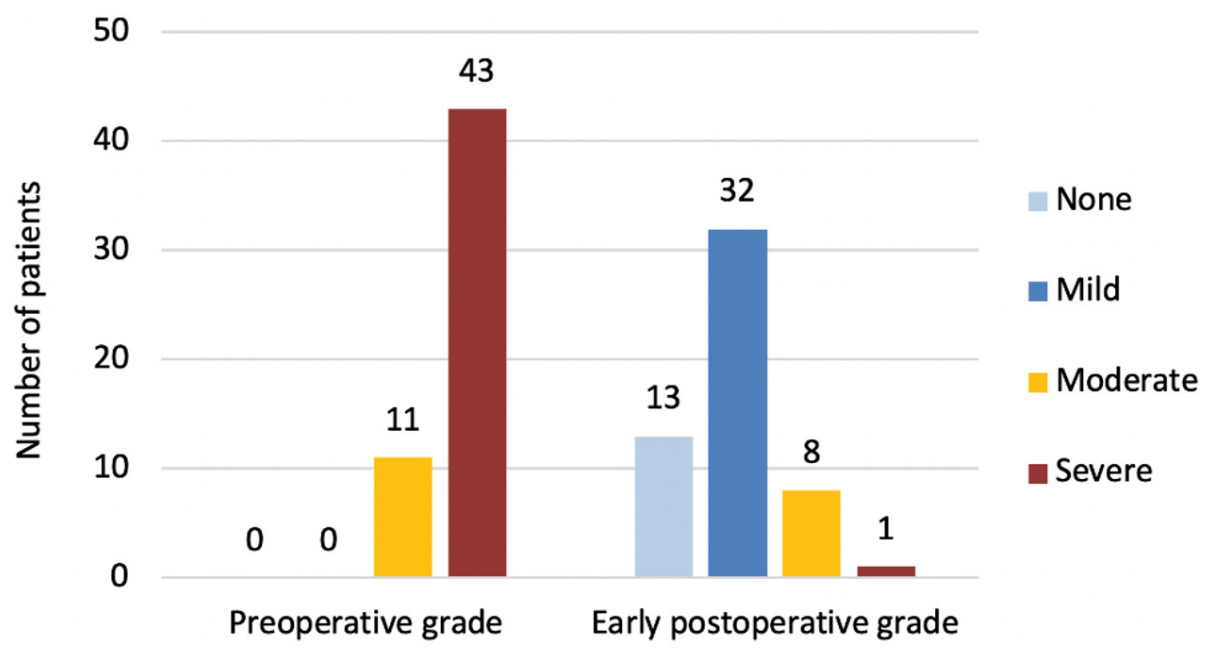

Figure 1 - Early postoperative changes in grades of tricuspid regurgitation.

Table 3 - Evaluation of tricuspid valve annuloplasty

\begin{tabular}{lccc}
\hline $\begin{array}{l}\text { Grade of the } \\
\text { tricuspid lesion }\end{array}$ & $\begin{array}{c}\text { Preoperative } \\
(\mathbf{n}=54)\end{array}$ & $\begin{array}{c}\text { Postoperative } \\
(\mathbf{n}=54)\end{array}$ & $\mathbf{p}$ \\
\hline $\begin{array}{l}\text { Normal valve or } \\
\text { mild lesion }\end{array}$ & $0(0 \%)$ & $45(83.33 \%)$ & \\
$\begin{array}{l}\text { Moderate } \\
\text { or severe } \\
\text { regurgitation }\end{array}$ & $54(100 \%)$ & $9(16.66 \%)$ & $0.0077^{*}$ \\
\hline
\end{tabular}

The McNemar's test was used for categorical variables - normal valve or mild lesions $x$ moderate or severe tricuspid regurgitation; ${ }^{*} p<0.05$.

outcome after valve repair, most of them had mild stenosis, normal valve or mild insufficiency in the postoperative period. Mild insufficiency, in the literature, has been identified as residual regurgitation, and may occur due to factors such as the degree of ring dilation, and right ventricular and left ventricular functions in the preoperative period. ${ }^{21,22}$

In addition, in our study, there was no significant decrease in the LVEF $(p=0.0774)$. The decrease in ejection fraction in the postoperative period of cardiac surgery is well recognized in the literature as an effect of extracorporeal circulation, ${ }^{23}$ but little is known about the mechanism that leads to this dysfunction. ${ }^{18,24}$

Although the tricuspid valve repair has reached its goal, complications exist and may not be uncommon.
The number of deaths in the recent postoperative period (up to 30 days) was $6.9 \%$ higher than in the international literature (2 to $4.5 \%){ }^{18,24}$

The most common complications in the early postoperative period after tricuspid valve repair in our sample were atrioventricular block, acute renal failure, respiratory tract infection, cardiorespiratory arrest and pericardial effusion. This is in agreement with previous studies, which also reported low cardiac output syndrome, bleeding, mediastinitis, sepsis and stroke, ${ }^{18,25}$ which were also observed in our patients, without a significant frequency though.

The present study has some limitations. First, since it is a retrospective and observational study, the study has limitations inherent to its design. Second, there was a difficulty during data collection due to lack of information in the medical records, reducing the sample size for some variables.

\section{Conclusion}

Although the clinical profile of the study patients was characterized by severe disease, with multivalvular heart disease and a large percentage of reoperations, the modified De Vega technique for repair of functional tricuspid insufficiency was effective and reproducible in our environment. There were favorable results with a significant reduction in the degree of tricuspid insufficiency. Further studies are needed to evaluate the 
outcomes of this surgery in the long term and in right heart valve disease.

\section{Potential Conflict of Interest}

No potential conflict of interest relevant to this article was reported.

\section{Sources of Funding}

There were no external funding sources for this study.

\section{Study Association}

This study is not associated with any thesis or dissertation work.

\section{Ethics approval and consent to participate}

This study was approved by the Ethics Committee of the IMIP under the protocol number 58349516.7.0000.5201.
All the procedures in this study were in accordance with the 1975 Helsinki Declaration, updated in 2013. Informed consent was obtained from all participants included in the study.

\section{Author contributions}

Conception and design of the research: Figueira FAMS, Ferraz, DLM. Acquisition of data: Alves KMB, Leandro GS, Santos LAB, D' Azevedo SSP, Silva TLS, Silva ITC, Tchaick RM. Analysis and interpretation of the data: Ferraz DLM, Monteiro VS, Cunha CBC. Statistical analysis: Ferraz, DLM. Writing of the manuscript: Alves KMB, Leandro GS, Santos LAB, Carvalho Junior JD, Oliveira JPSP, Walter FR, Ferraz DLM. Critical revision of the manuscript for intellectual content: Ferraz DLM.

12. Dordetto PR, Pinto GC, Rosa TCSC. Pacientes submetidos à cirurgia cardíaca: caracterização sociodemográfica, perfil clínico-epidemiológico e complicações. Rev Fac Ciênc Méd Sorocaba. 2016;18(3):144-9.

13. Moraes RCS, Katz M, Tarasoutch F. Clinical and epidemiological profile of patients with valvular heart disease admitted to the emergency department. Einstein. 2014;12(2):154-8

14. Shah PM. Tricuspid and pulmonary valve disease evaluation and management. Rev Esp Cardiol. 2010;63(11):1349-65.

15. McCarthy PM, Bhudia SK, Rajeswaran J, Hoercher KJ, Lytle BW Cosgrove DM, et al. Tricuspid valve repair: durability and risk factors for failure. J Thorac Cardiovasc Surg. 2004;127(3):675-85.

16. Koch CG, Li L, Shishehbor M, Nissen S, Sabik J, Starr NJ, et al Socioeconomic status and comorbidity as predictors of preoperative quality of life in cardiac surgery. J Thorac Cardiovasc Surg. 2008;136(3):665-72.

17. Tornos Mas P, Rodríguez-Palomares JF, Antunes MJ. Secondary tricuspid valve regurgitation: a forgotten entity. Heart. 2015;101(22):1840-8.

18. Hwang HY, Chang HW, Jeong DS, Ahn H. De Vega annuloplasty for functional tricuspid regurgitation: concept of tricuspid valve orifice index to optimize tricuspid valve annular reduction. J Korean Med Sci. 2013;28(12):1756-61.

19. Gosev I, Yammine M, McGurj S, Ejiofor JI, Norman A, Ivkovic V et al Should moderate-to-severe tricuspid regurgitation be repaired during reoperative left-sided valve procedures? Semin Thorac Cardiovasc Surg. 2016;28(1):38-45

20. Shiran A, Sagie A. Tricuspid regurgitation in mitral valve disease incidence, prognostic implications, mechanism, and management. J Am Coll Cardiol. 2009;53(5):401-8.

21. Fukuda S, Gillinov AM, McCarthy PM, Stewart WJ, Song JM, Kihara T, et al. Determinants of recurrent of residual functional tricuspid regurgitation after tricuspid annuloplasty. Circulation. 2006;114(1 suppl):I582-7.

22. De Hert SG, Rodrigus IE, Haenen LR, De Mulder PA, Gillebert TC. Recovery of systolic and diastolic left ventricular function early after cardiopulmonary bypass. Anesthesiology. 1996;85(5):1063-75. 
23. Kim JB, Jung SH, Choo SJ, Chung CH, Lee JW. Clinical and echocardiographic outcomes after surgery for severe isolated tricuspid regurgitation. J Thorac Cardiovasc Surg. 2013;146(2):278-84.

24. Lang RM, Badano LP, Mor-Avi V, Afilalo J, Armstrong A, Ernande $\mathrm{L}$, et al. Recommendations for cardiac chamber quantification by echocardiography in adults: an update from the American Society of
Echocardiography and the European Association of Cardiovascular Imaging. J Am Soc Echocardiogr. 2015;28(1):1-39.e14.

25. de Agustin JA, Martinez-Losas P, de Diego JJG, Mahia P, MarcosAlberca P, Nuñez-Gil IJ, et al. Tricuspid annular plane systolic excursion inaccuracy to assess right ventricular function in patients with previous tricuspid. Int J Cardiol. 2016 Nov 15;223:713-6. 